\title{
Rap2B promotes the proliferation and migration of human glioma cells via activation of the ERK pathway
}

\author{
GUOHONG SHI and ZHEN ZHANG \\ Department of Ultrasound, The First Hospital of China Medical University, \\ Shenyang, Liaoning 110001, P.R. China
}

Received September 3, 2020; Accepted February 2, 2021

DOI: $10.3892 / \mathrm{ol} .2021 .12575$

\begin{abstract}
Glioma is one of the most common primary brain tumors and has a poor prognosis. Rap2B, a member of the Ras family of oncogenes, is highly expressed and promotes the progression of several tumors, including glioma. However, the mechanism underlying the role of Rap2B in glioma is not fully understood. In the present study, after transfection, Rap2B expression was detected by reverse transcription PCR and western blot analysis. Cell proliferation and cell migration assays were performed to determine the effects of Rap2B on the malignant biological behaviors of glioma cells. The changes of ERK pathway-associated proteins were examined by western blot analysis. Enzyme-linked immunosorbent assay (ELISA) and western blot analysis were utilized to detect the protein levels of matrix metalloproteinase (MMP)2 and MMP9. Then, The Cancer Genome Atlas database was used to determine the association between Rap2B expression and clinical parameters in patients with glioblastoma multiforme and low-grade glioma (LGG). Results revealed that Rap2B was highly expressed in human glioma compared with that in adjacent normal tissues and normal human astrocytes, and that silenced Rap2B led to a reduction of cell proliferation and migration ability in glioma cells. Conversely, overexpressed Rap2B in both U87 and U251 cells significantly enhanced these malignant activities. In addition, ELISA assay and western blotting showed that Rap2B increased MMP2 and MMP9 expression. The western blot assay revealed that Rap2B induced the phosphorylation of ERK in glioma cells. Furthermore, silencing the ERK pathway by SCH772984 led to the inhibition of Rap2B-mediated proliferation, migration and the reduction of MMP2 and MMP9 expression. Kaplan-Meier analysis revealed that increased Rap2B expression was associated with poorer survival of patients with LGG. These results demonstrated that Rap2B may participate in the processes of
\end{abstract}

Correspondence to: Dr Zhen Zhang, Department of Ultrasound, The First Hospital of China Medical University, 155 Nanjing North Street, Shenyang, Liaoning 110001, P.R. China

E-mail: 2662898158@qq.com

Key words: ERK pathway, glioma, Rap2B glioma cell proliferation and migration through enhancing MMP2 and MMP9 expression via the ERK pathway. Thus, Rap2B could potentially be used as a promising therapeutic target and prognostic biomarker in glioma.

\section{Introduction}

Gliomas account for $80 \%$ of all malignant primary brain tumors, with an annual incidence of approximately 6 per 100,000 in the USA (1). Despite great advances in therapeutic strategies in the past decade, including surgical resection, radiotherapy and chemotherapy, the prognosis of patients with glioma remains unsatisfactory due to high metastasis and recurrence, with a median survival of only 10-14 months (2). Therefore, it is important to understand the molecular mechanisms underlying tumorigenesis and progression of glioma in order to identify novel therapeutic targets.

The ERK signaling pathway is one of the most frequently activated pathways in various human tumors, including glioma. The ERK pathway is involved in regulation of multiple biological functions, including cell proliferation, differentiation, apoptosis, migration and invasion (3-6). Tumor metastasis requires tumor cell-derived proteases, especially matrix metalloproteinases (MMPs), to degrade the extracellular matrix (ECM) $(7,8)$. MMPs have been demonstrated to be crucial for the invasive and metastatic potential of a variety of malignant tumors, such as breast, lung and pancreatic cancer (9). Among the MMPs, the present study focused on MMP2 and MMP9, which were shown to promote glioma cell motility (10). However, the underlying mechanism of MMP2 and MMP9 in glioma remains unclear.

Rap proteins are a subgroup of the Ras family; a group of small guanosine 5' triphosphate (GTP) binding proteins with five different isoforms: Rap1A, Rap1B, Rap2A, Rap2B and Rap2C (11). Rap2B, a member of the Ras oncogene family, is highly expressed in diverse types of tumors, including colorectal cancer (12), hepatocellular carcinoma (13) and lung cancer (14). Similar to other Ras proteins, Rap2B can be activated and inhibited by a variety of external and internal inducers, circulating between its GTP-bound active state and GDP-bound inactive state (15). Several studies have reported that Rap2B has a critical regulatory role in a series of cellular biological processes, such as cell adhesion, proliferation, migration and invasion, as well as signal transduction in 
human cells $(16,17)$. The association between Rap2B and tumorigenesis has been previously confirmed, for example Rap2B promotes the tumor growth in vivo in renal cell carcinoma (18) and, in prostate cancer, Rap2B regulates tumor growth and metastasis through the focal adhesion kinase pathway (19). Additionally, Rap2B is a direct target gene of p53 and functions in a p53-dependent manner in the regulation of apoptosis and migration (20). Zhang et al (21) reported that miR-194 suppresses cell proliferation and invasion of bladder cancer by targeting Rap2B expression. Miao et al (22) showed that Rap2B-knockdown inhibits the malignant behaviors of glioma cells through the NF- $\mathrm{B}$ pathway. However, the molecular mechanism of Rap2B in glioma has not yet been fully elucidated.

The present study investigated the protein and mRNA expression levels of Rap2B in glioma cells and tissues, as well as the role of Rap2B in regulating the biological activities of glioma cells via using bi-directional regulation of Rap2B. Additionally, the correlation between Rap2B expression and disease characteristics or patient survival was further analyzed in this study.

\section{Materials and methods}

Cell culture. Normal human astrocytes (NHAs) were purchased from a typical cell culture collection Committee of the Chinese Academy of Sciences Library and cultured in RPMI-1640 culture medium (Gibco; Thermo Fisher Scientific, Inc.). Human glioma cell lines U87 (a glioblastoma of unknown origin) and U251 were purchased from The Cell Bank of Type Culture Collection of The Chinese Academy of Sciences and cultured in DMEM/high glucose (HyClone; Cytiva). These media were supplemented with 10\% FBS (HyClone; Cytiva) and $1 \%$ penicillin-streptomycin. All cells were placed in an incubator with $5 \% \mathrm{CO}_{2}$ at $37^{\circ} \mathrm{C}$.

Cell transfection. Untransfected glioma cells were used as the control group. Small interfering RNA against Rap2B (si-Rap2B) and non-targeting negative control (si-NC) were purchased from Guangzhou RiboBio Co., Ltd. The following sequences were used to knockdown Rap2B: siRNA, 5'-CGACCAUCGAAGACUUUUATT-3' (Sense) and 5'-UAAAAGUCUUCGAUGGUCGTT-3' (antisense). Glioma cells were transfected with $50 \mathrm{nM}$ si-Rap2B or $50 \mathrm{nM}$ si-NC until cell density reached $\sim 50 \%$ confluence by riboFECT CP reagent (Guangzhou RiboBio Co., Ltd.) based on the manufacturer's indication. The overexpression plasmids of pcDNA3.1-Rap2B (oe-Rap2B) and pcDNA3.1-vector (oe-NC) were designed and synthesized by Shanghai GeneChem Co., Ltd. When cell confluence reached $\sim 90 \%$, cells were transfected with $5 \mu \mathrm{g}$ overexpression plasmids using Lipofectamine ${ }^{\circledR} 3000$ (Invitrogen; Thermo Fisher Scientific, Inc.) based on the manufacturer's instructions. The medium was changed to serum-free medium without penicillin and streptomycin prior to the transfection. Then, cells were subjected to subsequent experimentation $48 \mathrm{~h}$ following transfection.

Cell Counting Kit (CCK)-8 assay. Cell proliferation was measured using CCK-8 (Dojindo Molecular Technologies, Inc.) according to the manufacturer's instruction. Briefly, transfected cells were planted into 96-well plates at a density of 2,500 cells/well, and cultured for $24-72 \mathrm{~h}$. Then, $10 \mu \mathrm{l}$ of CCK-8 solution was added to each well and the plates were further incubated for $2 \mathrm{~h}$ at $37^{\circ} \mathrm{C}$. The absorbance was measured at $450 \mathrm{~nm}$ using a scanning microplate absorbance reader (Thermo Fisher Scientific, Inc.).

5-Ethynyl-2'-deoxyuridine (EdU) assay. After transfection, U87 and U251 cells were seeded into 96-well plates and cultured in serum-free medium for $24 \mathrm{~h}$ incubation at $37^{\circ} \mathrm{C}$. When cell confluence reached $60 \%$, each well was incubated with $100 \mu \mathrm{l}$ diluted EdU solution for $2 \mathrm{~h}$ at $37^{\circ} \mathrm{C}$. The EdU kit (cat. no. C10310-1) was obtained from Guangzhou RiboBio Co., Ltd. Subsequently, the nuclei could be found using an inverted fluorescence microscope (Nikon Corporation). Then, we counted each well at 5 different microscope fields under a fluorescence microscope (magnification, x200). The quantitative data were presented as the percentage of EdU-positive nuclei relative to total number of nuclei counted using ImageJ (version 1.52q; National Institutes of Health). The experiment was performed in triplicate.

Cell migration assay. Cell migration was carried out using two-chamber plates with pore size of $8 \mu \mathrm{m}$. After transfection, $2 \times 10^{4}$ glioma cells were placed into the upper chambers with serum-free medium, and $500 \mu 1$ of DMEM (HyClone; Cytiva) containing 20\% FBS (HyClone; Cytiva) was added to the lower chambers. After incubation at $37^{\circ} \mathrm{C}$ for $24 \mathrm{~h}$, the cells remaining in the upper chambers were removed with cotton swabs. The migrated cells in the lower chambers were fixed with $100 \%$ methanol for $20 \mathrm{~min}$ at room temperature and stained with $0.1 \%$ crystal violet for $30 \mathrm{~min}$ at room temperature. In total, eight microscopy fields on the lower surface of each chamber were randomly chosen, and images were captured using an inverted fluorescence microscope (Nikon Corporation).

Enzyme-linked immunosorbent assay (ELISA). The supernatant of transfected U87 and U251 cells were collected from each group after $24 \mathrm{~h}$. The Human Matrix MetalloProteinase (MMP)2 ELISA (cat. no. ab100606; Abcam) and MMP9 ELISA kits (cat. no. ab100610; Abcam) were used to detect the concentrations of MMP2 and MMP9 based on the manufacturer's guidelines. The absorbance at $450 \mathrm{~nm}$ wavelength was recorded using the microplate reader (Thermo Fisher Scientific, Inc.).

Reverse transcription-quantitative (RT-q)PCR analysis. Total RNA was extracted from transfected U87 and U251 cells using TRIzol $^{\circledR}$ (Invitrogen, Thermo Fisher Scientific, Inc.). cDNA was synthesized using the Reverse Transcription kit (Takara Bio, Inc.) according to the manufacturer's protocol. qPCR was performed using SYBR ${ }^{\circledR}$ Premix Ex Taq ${ }^{\mathrm{TM}}$ II kit (Takara Bio, Inc.) on Light Cycler 480 instrument (Roche Diagnostics). The following thermocycling conditions were used: Initial denaturation at $95^{\circ} \mathrm{C}$ for $30 \mathrm{sec}, 45$ cycles of $95^{\circ} \mathrm{C}$ for $5 \mathrm{sec}, 60^{\circ} \mathrm{C}$ for $30 \mathrm{sec}$, melting curve at $95^{\circ} \mathrm{C}$ for $5 \mathrm{sec}, 60^{\circ} \mathrm{C}$ for $60 \mathrm{sec}, 95^{\circ} \mathrm{C}$ for $5 \mathrm{sec}$, and cooling at $50^{\circ} \mathrm{C}$ for $30 \mathrm{sec}$. The primers were as follows:Rap2B,Forward:5'-TTACCGCAAGGAGATTGAG-3', reverse: 5'-GGCTGTAGACCAGGATGAAG-3'; GAPDH, forward: 5'-GAAGGTGAAGGTCGGAGT-3', reverse: 
5'-GAAGATGGTGATGGGATTTC-3'. The $2^{-\Delta \Delta C q}$ method was used to calculate gene expression (23), and GAPDH was selected as the internal reference.

Western blotting. Total proteins from cultured glioma cells were extracted using RIPA lysis buffer (Beyotime Institute of Biotechnology) and their concentrations were determined using a bicinchoninic acidprotein assay reagent kit (cat. no. P0010S; Beyotime Institute of Biotechnology). A total of $30 \mu \mathrm{g}$ proteins were loaded per lane and separated via 10\% SDS-PAGE, then transferred to a PVDF membrane (Bio-Rad Laboratories, Inc.). After blocking with 5\% fat-free milk for $2 \mathrm{~h}$ at room temperature, the membranes were incubated with primary antibodies overnight at $4^{\circ} \mathrm{C}$. After washing with TBS-Tween-20 ( $0.5 \%$ Tween), the membranes were incubated with secondary antibody for $1 \mathrm{~h}$ at $37^{\circ} \mathrm{C}$. Image Lab software version 3.0 (Bio-Rad Laboratories, Inc.) was used to detect the protein bands, and proteins were visualized using enhanced chemiluminescent substrate (Thermo Fisher Scientific, Inc.). The antibodies used were: Rap2B (cat. no. ab101369; 1:1,000), MMP-2 (cat. no. ab92536; 1:1,000), MMP-9 (cat. no. ab76003; 1:1,000), ERK (cat. no. ab184699; 1:10,000) and phosphorylated (p)-ERK (cat. no. ab76299; 1:5,000) (all Abcam). Secondary antibody (cat. no. SA00001-2; 1:2,000) and GAPDH (cat. no. 10494-1-AP; 1:10,000) were purchased from ProteinTech Group, Inc.

Acquisition of clinical parameters and RNA-sequencing data. The clinical and Rap2B expression data of 156 cases of patients with glioblastoma multiforme (GBM) and 511 cases of low-grade glioma (LGG) were acquired from the dataset (Project ID: TCGA-GBM and TCGA-LGG) in The Cancer Genome Atlas (TCGA) database (https://portal.gdc.cancer. gov/). Then, the normalized mRNA count ('count'), which represented Rap2B gene expression, was used. Exclusion criteria were those samples with histological diagnosis excluding GBM or LGG and incomplete RNA-sequencing data. Finally, Rap2B expression files containing GBM (152 GBM tissues; five matched normal tissues) and 509 LGG (248 grade 2; 261 grade 3) were downloaded from TCGA project. The grading system was based on the World Health Organization classification (24).

Statistical analysis. All experiments were independently repeated at least three times. Data were analyzed with SPSS 19.0 software (IBM Corp.) and GraphPad Prism 6.01 software (GraphPad Software, Inc.) and presented as mean \pm standard deviations. Comparisons between two groups were executed using Student's t-test. Comparisons among $\geq 3$ groups were performed using one-way ANOVA followed by Tukey's test. $\chi^{2}$ or Fisher's exact tests were performed to assess the relationship between Rap2B expression and clinicopathological characteristics. Then, the survival curves of Rap2B were plotted using Kaplan-Meier analysis based on the log-rank test. $\mathrm{P}<0.05$ was considered to indicate a statistically significant difference.

\section{Results}

Rap2B upregulation in human glioma. Compared with NHA, the results of western blotting showed that the protein level of Rap2B in U87 and U251 cells was upregulated (Fig. 1A; $\mathrm{P}<0.001)$. To confirm these findings, Rap2B expression was further analyzed using TCGA database. The results revealed that Rap2B expression was significantly upregulated in 152 GBM tissues compared with that in five matched normal tissues (Fig. 1B; $\mathrm{P}=0.0372$ ). In 509 patients with LGG, Rap2B expression in patients with tumor grade 3 was significantly higher compared with patients with tumor grade 2 (Fig. 1C; $\mathrm{P}<0.0001)$. Among histological types of LGG, Rap2B from astrocytoma was more highly expressed compared with oligodendroglioma based on TCGA-LGG dataset (Fig. 1D; $\mathrm{P}=0.001)$. The results demonstrated that Rap2B was upregulated and associated with tumor grade and histological type in human glioma.

Then, Rap2B was simultaneously silenced or overexpressed in U87 and U251 cells. No significant difference was observed in the levels of Rap2B mRNA and protein between the control group and the respective $\mathrm{NC}$ group (Fig. 1E and F). Relative to the respective NC group, mRNA and protein expression of Rap2B in both U87 and U251 cells was decreased in the silenced Rap2B group (Fig. 1E; $P<0.05$ ) and increased in the overexpressed Rap2B group (Fig. 1F; $\mathrm{P}<0.001)$.

Silenced or overexpressed Rap $2 B$ influences proliferation of glioma cells. To investigate whether Rap2B affects the proliferation of glioma cells, a CCK- 8 assay was performed. It was observed that there was no significant difference in cell proliferation between the respective $\mathrm{NC}$ and control groups. The CCK- 8 assay revealed that proliferation rates of U87 and U251 cells were significantly reduced in the si-Rap2B group (Fig. 2A; $\mathrm{P}<0.05$ ), but significantly enhanced in the Rap2B-overexpression group compared with the corresponding NC group (Fig. 2B; $\mathrm{P}<0.05$ ). To further verify the effect of Rap2B on glioma cell proliferation, an EdU assay was conducted. Similar results were obtained, showing a significant decrease in the number of EdU-positive glioma cells with Rap2B-knockdown (Fig. $2 \mathrm{C}$; $\mathrm{P}<0.05$ ), while the number of EdU-positive glioma cells transfected with Rap2B overexpression plasmids was significantly elevated relative to the corresponding $\mathrm{NC}$ group (Fig. 2D; $\mathrm{P}<0.05$ ). The inhibitor $\mathrm{SCH} 772984$ weakened this promotive effect of proliferation elicited by overexpressed Rap2B in both U87 and U251 cells $(\mathrm{P}<0.05$; Fig. $2 \mathrm{~B}$ and $\mathrm{D})$, suggesting the involvement of ERK pathway in regulating Rap2B-mediated proliferation. The aforementioned results demonstrated that the alterations of Rap2B were closely associated with the proliferation of glioma cells.

Silenced or overexpressed Rap $2 B$ influences migration of glioma cells. The effect of Rap2B on the migration ability of glioma cells was evaluated using a cell migration assay. Compared with the NC group, Rap2B-knockdown significantly reduced the migration ability of U87 and U251 cells (Fig. 3A; P<0.05), whereas Rap2B overexpression led to a significantly enhanced migration ability (Fig. 3B; $\mathrm{P}<0.001$ ). No significant difference could be observed in the migration of U87 and U251 cells between the control group and relative NC group. These results indicated that Rap2B could promote the migration ability of glioma cells. 

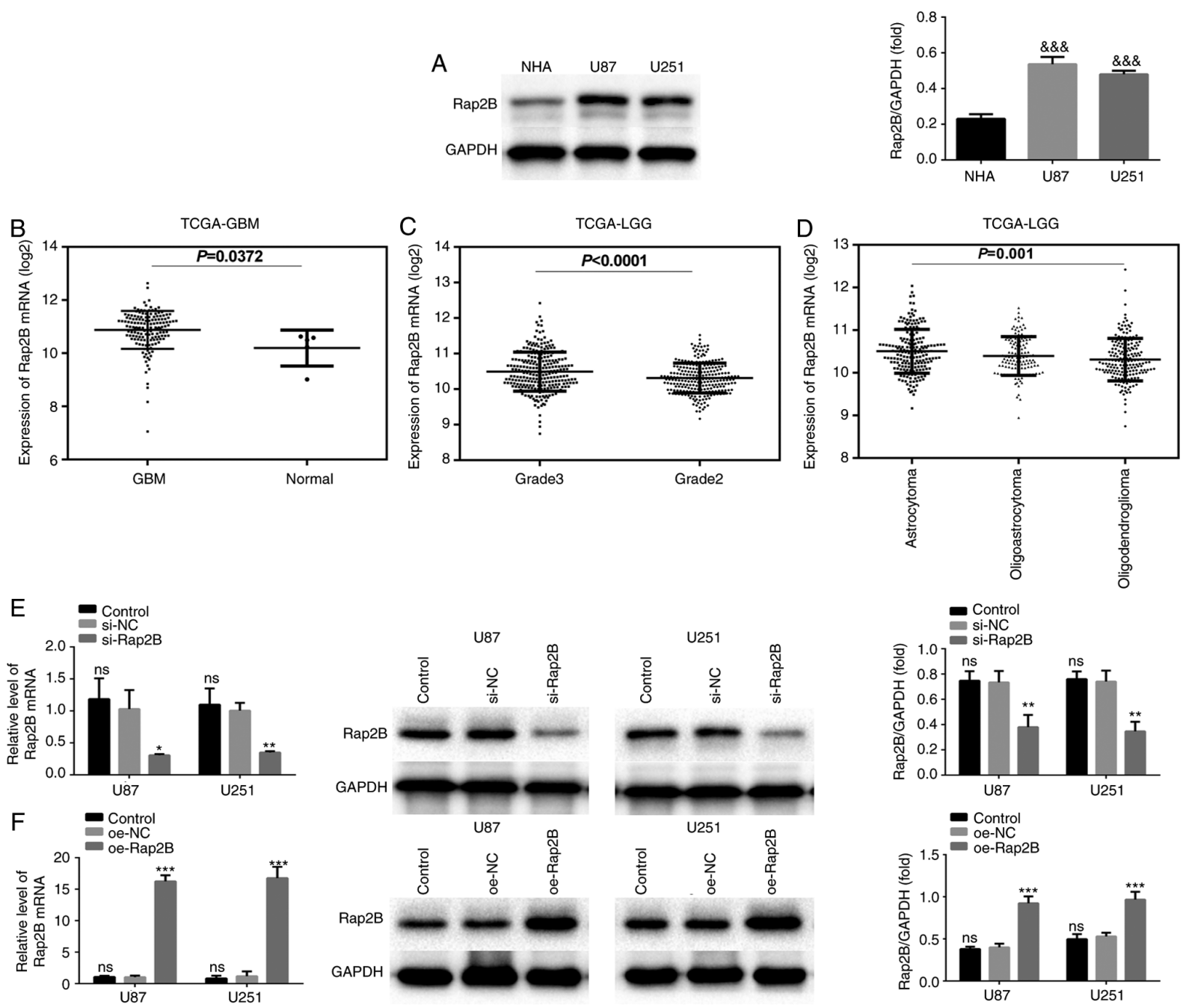

Figure 1. Rap2B expression in glioma. (A) Expression of Rap2B analyzed using western blot analysis in NHA, U87 and U251 cells. (B) Rap2B expression was elevated in $152 \mathrm{GBM}$ samples compared with that in five adjacent normal samples in the TCGA-GBM dataset. (C) In the TCGA-LGG dataset, Rap2B expression in patients with tumor grade $3(\mathrm{n}=261)$ was notably higher compared with patients with tumor grade $2(\mathrm{n}=248)$. (D) Rap2B in astrocytoma ( $\mathrm{n}=192)$ was upregulated relative to oligodendroglioma $(n=190)$ based on TCGA-LGG dataset. (E) Detection of Rap2B-silencing in U87 and U251 cells. (F) Detection of Rap2B overexpression in U87 and U251 cells. ${ }^{\text {\&\&\&}} \mathrm{P}<0.001$ vs. NHA. ${ }^{*} \mathrm{P}<0.05,{ }^{* *} \mathrm{P}<0.01$ and ${ }^{* * *} \mathrm{P}<0.001$ vs. the corresponding NC group. TCGA, The Cancer Genome Atlas; GBM, glioblastoma multiforme; LGG, low-grade glioma; NHA, normal human astrocyte; NC, negative control; ns, no statistical significance; si, short interfering; oe, overexpressed.

Rap2B enhances MMP2 and MMP9 expression in glioma cells. To investigate whether Rap2B could increase MMP expression, an ELISA assay and western blotting were performed to examine the expression of MMP2 and MMP9. As shown in Fig. 4A, Rap2B-overexpressing U87 and U251 cells presented significant increases in protein levels of MMP2 and MMP9 in the supernatant of glioma cells $(\mathrm{P}<0.01)$. Rap2B expression in U87 and U251 cells was silenced by Rap2B siRNA to determine the effect on protein expression of MMP2 and MMP9. The results suggested that Rap2B-knockdown attenuated the secretion of MMP2 and MMP9 compared with the $\mathrm{NC}$ group in $\mathrm{U} 87$ and $\mathrm{U} 251$ cells (all $\mathrm{P}<0.05$; Fig. 4B). Moreover, this was corroborated by western blot analysis, showing the increased levels of MMP2 and MMP9 in the overexpressed Rap2B group and decreased MMP2 and MMP9 expression in Rap2B-silenced U87 and U251 cells compared with the $\mathrm{NC}$ group (all $\mathrm{P}<0.01$ or $\mathrm{P}<0.001$; Fig. $4 \mathrm{C}$ and $\mathrm{D}$ ). Collectively, these results demonstrated that Rap2B facilitated the expression of MMP2 and MMP9.
Rap $2 B$ is associated with the activation of the ERK pathway. Rap2B could potentially activate multiple pathways, such as MAPK/ERK, PI3K/AKT and NF-kB $(22,25,26)$. To analyze whether Rap2B could lead to ERK activation, glioma cells were transfected with Rap2B-overexpression plasmids. Western blot analysis revealed that the phosphorylation of ERK was significantly enhanced in Rap2B-overexpressing U87 and U251 cells compared with that in the NC group (Fig. 5B; $\mathrm{P}<0.001$ ). However, SCH772984 (an ERK pathway inhibitor) reversed the promotion in the phosphorylation of ERK mediated by Rap2B-overexpression in U87 and U251 cells $(\mathrm{P}<0.05)$. In contrast, the level of ERK phosphorylation was attenuated in Rap2B-silenced U87 and U251 cells relative to the NC group (Fig. 5A; P<0.001). These findings demonstrated that Rap2B significantly promoted ERK activation in glioma cells.

Effects of ERK signaling on Rap2B-induced cell proliferation, migration and expression of MMP2 and MMP9. To further confirm the involvement of ERK pathway in 

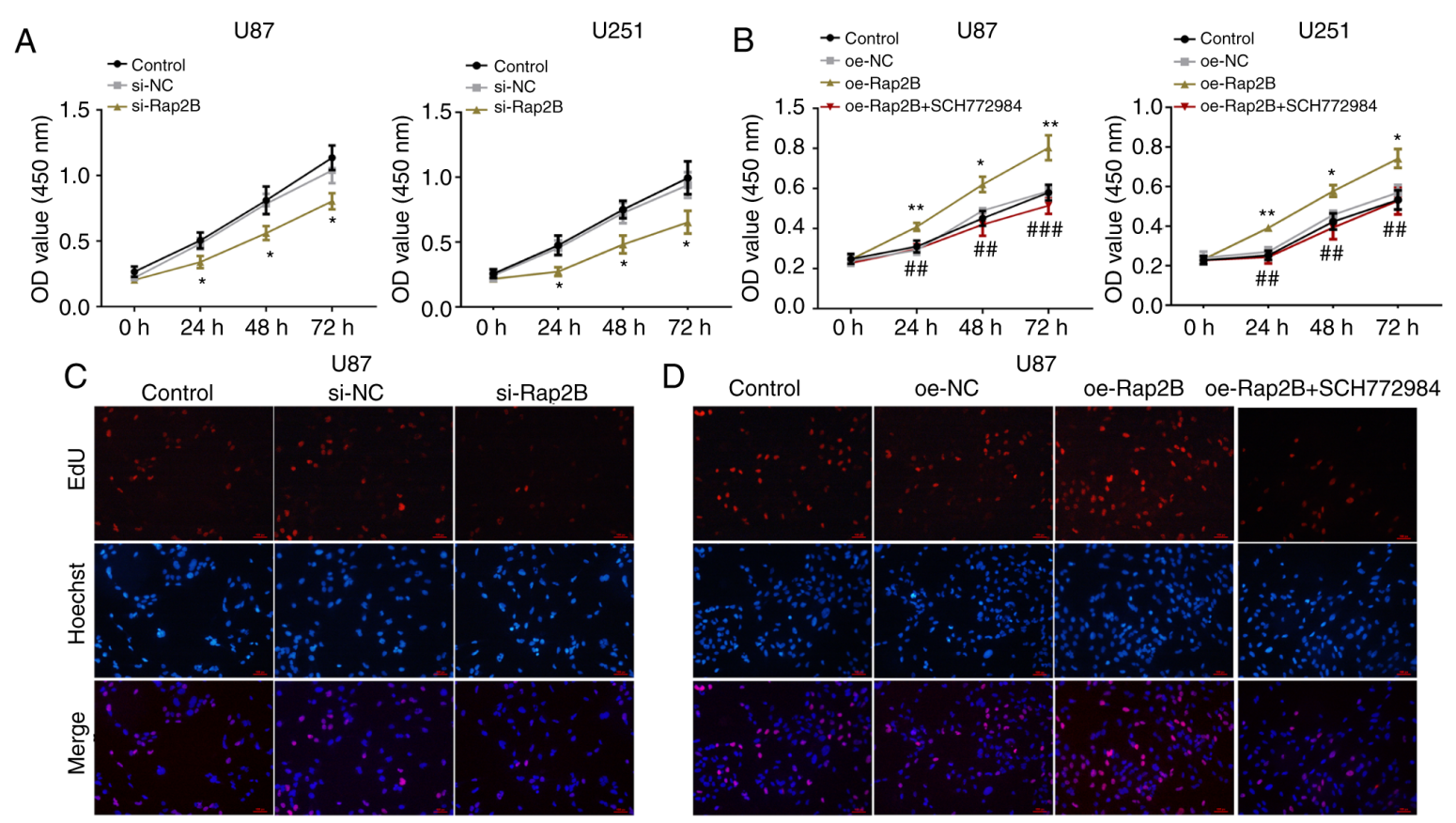

U251

U251
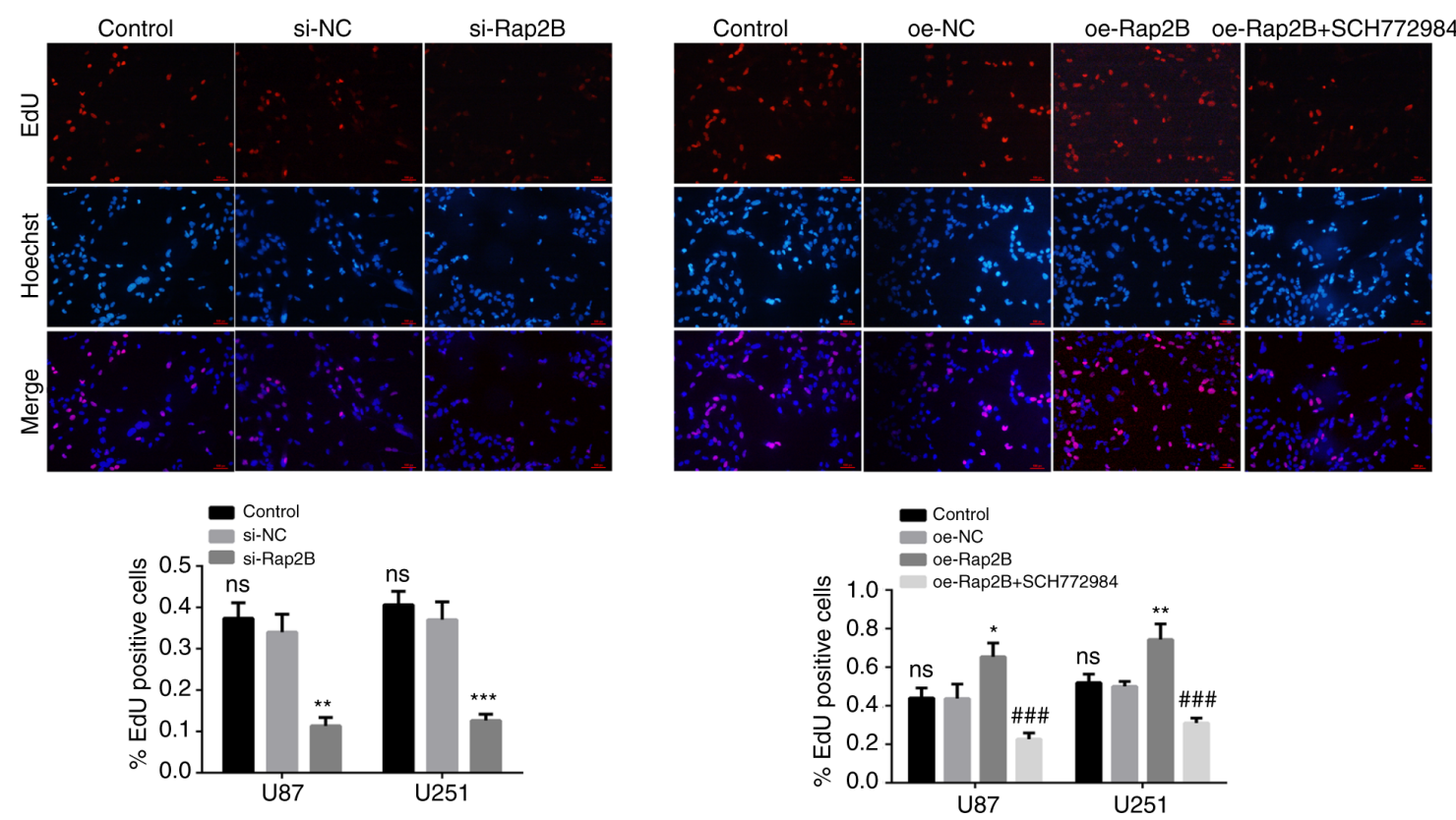

Figure 2. Effect of Rap2B on proliferation of glioma cells. (A) CCK-8 assay showed that silenced Rap2B suppressed glioma cell proliferation. (B) CCK-8 assay showed that overexpressed Rap2B enhanced glioma cell proliferation, while SCH772984 restrained their proliferation. (C and D) An EdU assay was performed to further determine the proliferation ability of glioma cells. Magnification, $\mathrm{x} 200 .{ }^{*} \mathrm{P}<0.05,{ }^{* * *} \mathrm{P}<0.01$ and ${ }^{* * * *} \mathrm{P}<0.001$ vs. the corresponding $\mathrm{NC}$ group. ${ }^{\# \#} \mathrm{P}<0.01$ and ${ }^{\# \# \#<0.001 ~ v s . ~ t h e ~ o v e r e x p r e s s e d ~ R a p 2 B ~ g r o u p . ~ N C, ~ n e g a t i v e ~ c o n t r o l ; ~ n s, ~ n o ~ s t a t i s t i c a l ~ s i g n i f i c a n c e ; ~ C C K-8, ~ C e l l ~ C o u n t i n g ~ K i t ~ 8 ; ~ s i, ~ s h o r t ~ i n t e r f e r i n g ; ~}$ oe, overexpressed.

Rap2B-stimulated secretion of MMP2 and MMP9, glioma cells were treated with SCH772984. As presented in Figs. 2B-D and 3B, it was observed that SCH772984 significantly weakened Rap2B-induced promotion of proliferation and migration of glioma cells $(\mathrm{P}<0.05)$, indicating that ERK signaling was required for proliferation and migration induced by Rap2B. Moreover, the results of the ELISA assays and western blotting showed that MMP2 and MMP9 expression was significantly reduced following co-treatment with Rap2B and SCH772984 compared with that in the overexpressed Rap2B group (all $\mathrm{P}<0.05, \mathrm{P}<0.01$ or $\mathrm{P}<0.001$; Fig. 6A-D).
Hence, inhibition of ERK pathway using SCH772984 treatment could restrain Rap2B-mediated production of MMP2 and MMP9 (Fig. 6A-D), demonstrating the involvement of ERK signaling in modulating Rap2B-stimulated MMP2 and MMP9 production.

Association of Rap2B expression with clinical parameters in 152 GBM and 509 LGG samples. As Rap2B expression promoted the proliferation and migration of glioma cells, the association between Rap2B expression and clinical features in GBM and LGG was further analyzed using TCGA database. 

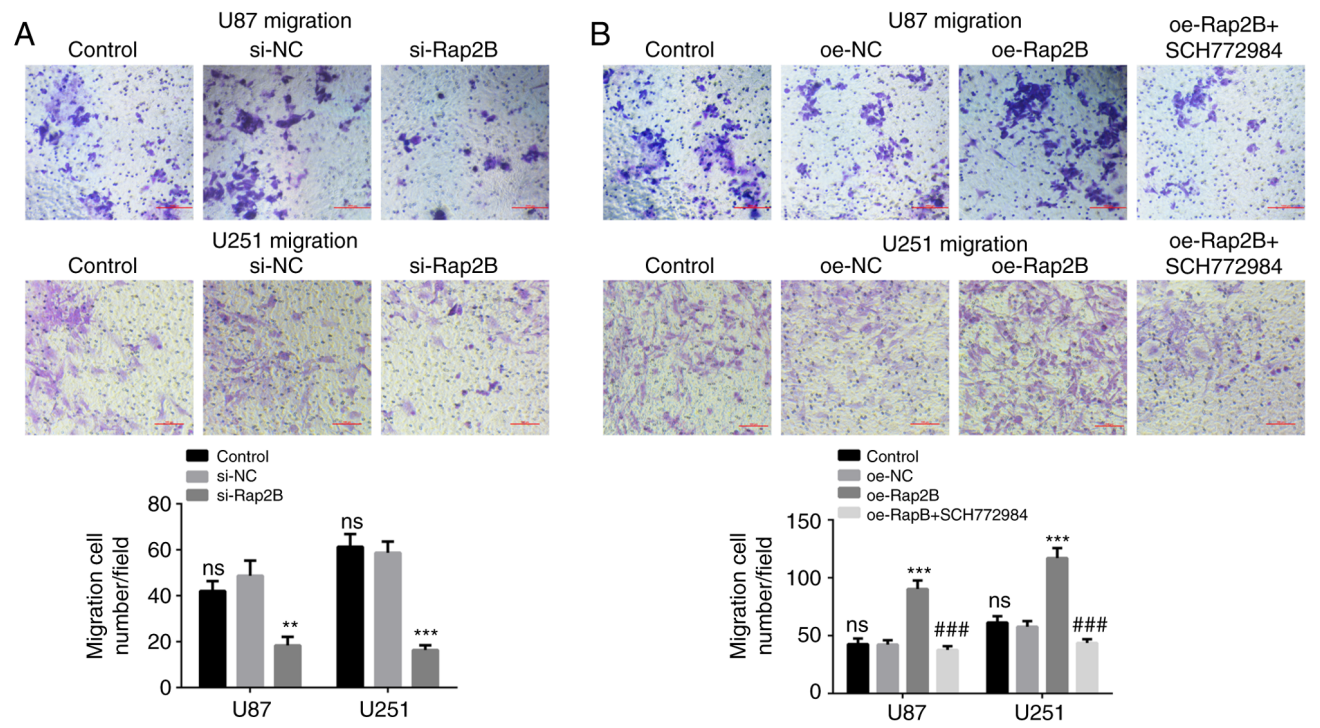

Figure 3. Effect of Rap2B on migration of glioma cells. (A) Transwell migration assay revealed that silenced Rap2B in U87 and U251 cells suppressed cell migration. (B) Overexpressed-Rap2B contributed to the migration of glioma cells. Glioma cells treated with SCH772984 exhibited reduced cell migration. Magnification, $x 200 .{ }^{* *} \mathrm{P}<0.01$ and ${ }^{* * *} \mathrm{P}<0.001$ vs. the corresponding NC group. ${ }^{\# \#} \mathrm{P}<0.001$ vs. the overexpressed Rap2B group. NC, negative control; ns, no statistical significance; si, short interfering; oe, overexpressed.

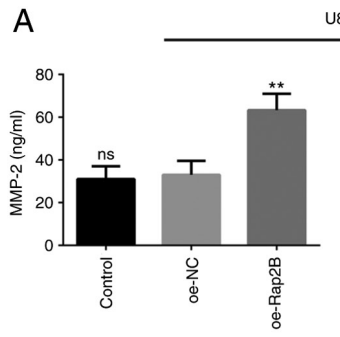

U87
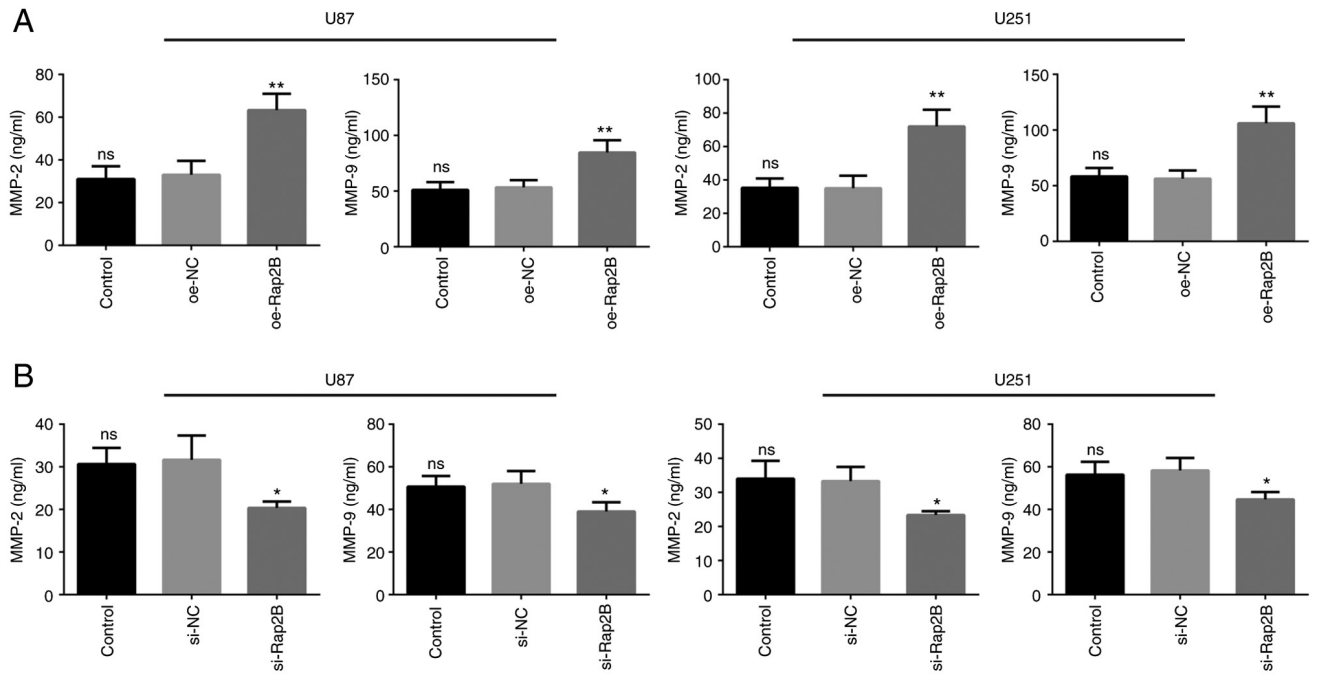

U251
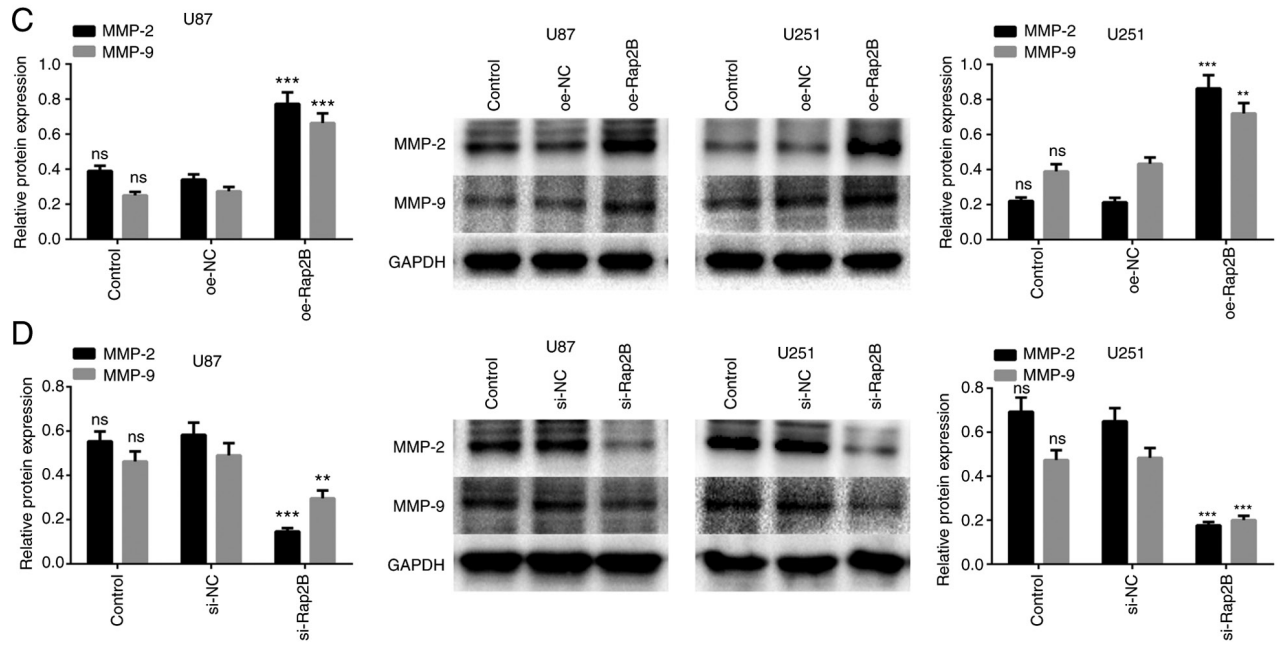

Figure 4. Effects of Rap2B on MMP2 and MMP9 expression in glioma cells. (A) After glioma cells were treated with Rap2B overexpression plasmids, an ELISA assay was employed to examine the secretion of MMP2 and MMP9. (B) Following the silencing of Rap2B, an ELISA was used to detect MMP2 and MMP9 expression in the supernatant of glioma cells. Western blot analysis and protein quantification revealed the protein levels of MMP2 and MMP9 following treatment with $(\mathrm{C})$ overexpressed and (D) knocked down Rap2B. ${ }^{*} \mathrm{P}<0.05,{ }^{* * *} \mathrm{P}<0.01$ and ${ }^{* * * *} \mathrm{P}<0.001$ vs. the corresponding $\mathrm{NC}$ group. NC, negative control; ns, no statistical significance; MMP, matrix metalloproteinase; si, short interfering; oe, overexpressed; ELISA, enzyme-linked immunosorbent assay. 

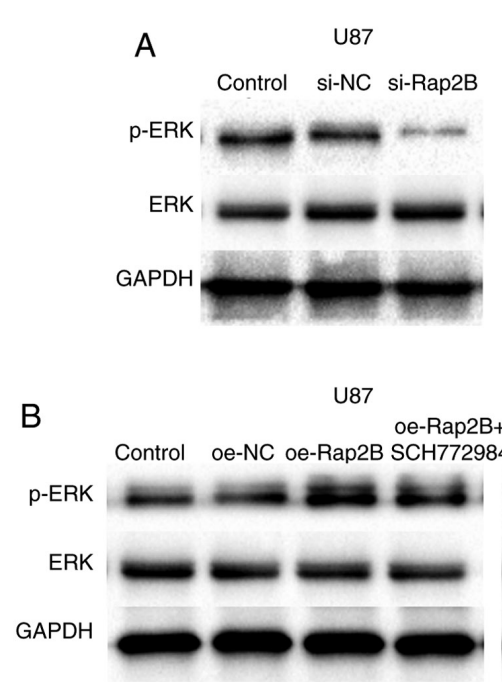

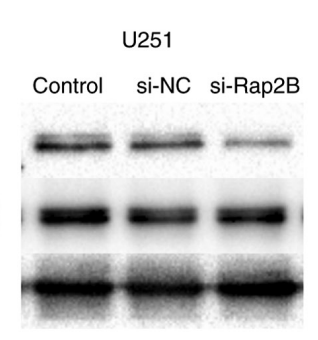

U251
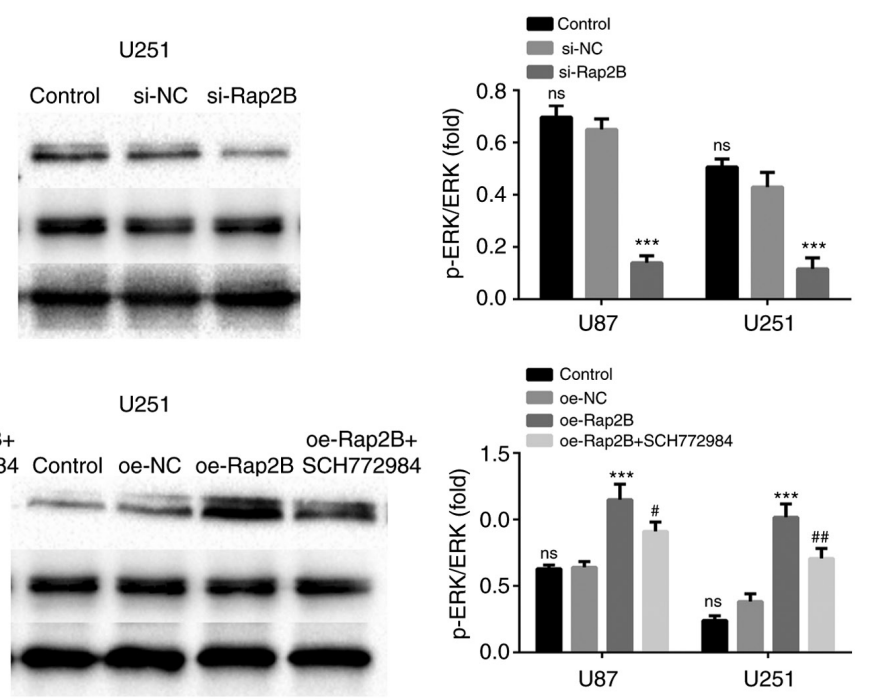

Figure 5. Rap2B activates the ERK pathway. (A) Western blot analysis showed that the protein expression of p-ERK was significantly reduced in Rap2B-silencing U87 and U251 cells. (B) Level of p-ERK was significantly increased in Rap2B-overexpressing U87 and U251 cells. Treatment with SCH772984 suppressed p-ERK expression. ${ }^{* * *} \mathrm{P}<0.001$ vs. the corresponding $\mathrm{NC}$ group. ${ }^{\#} \mathrm{P}<0.05$ and ${ }^{\# \#} \mathrm{P}<0.01$ vs. the overexpressed Rap2B group. NC, negative control; ns, no statistical significance; p-, phosphorylated; si, short interfering; oe, overexpressed.

A

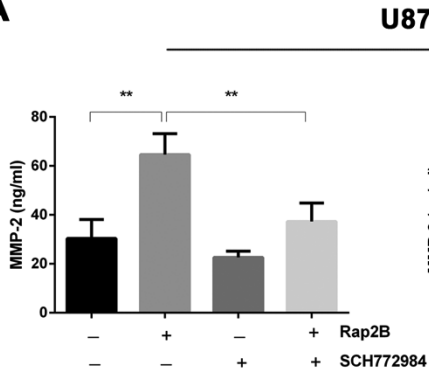

C

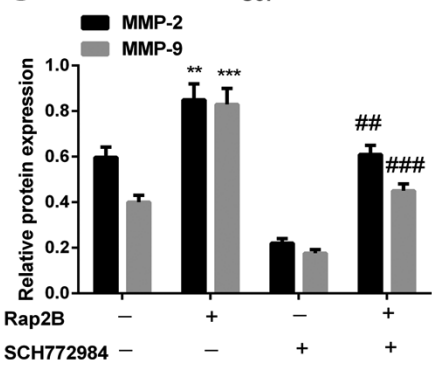

U87

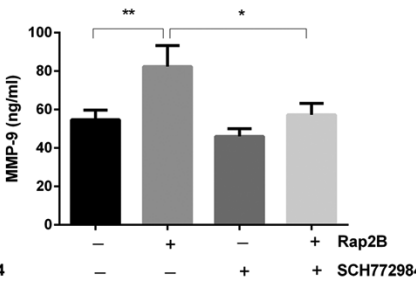

U87

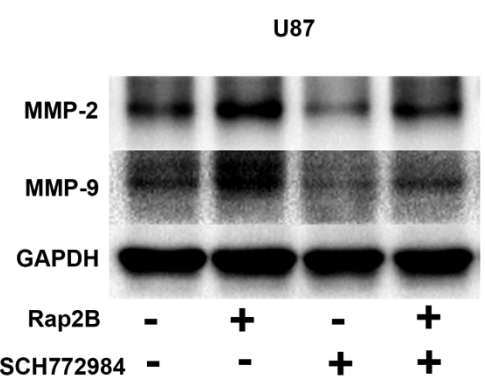

B

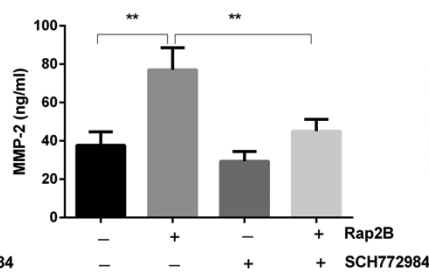

D
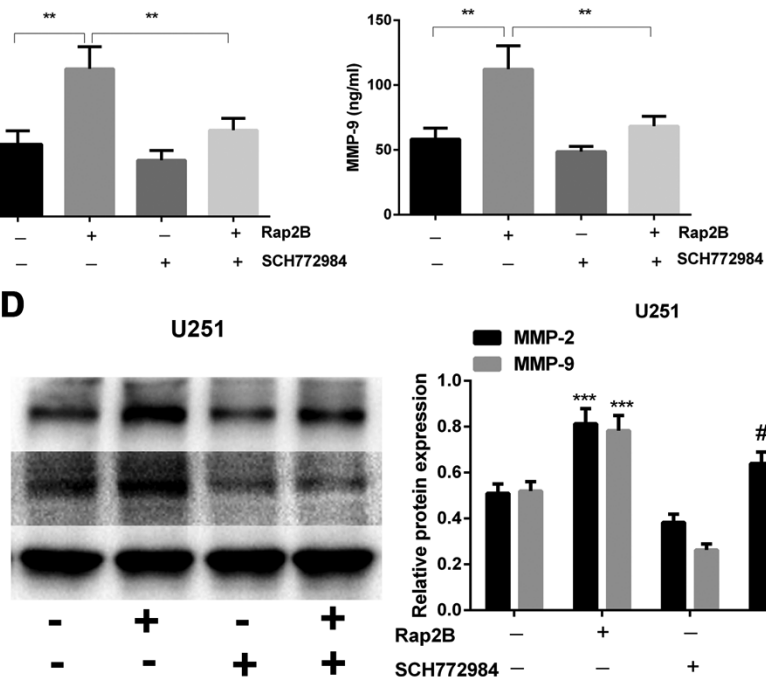

U251

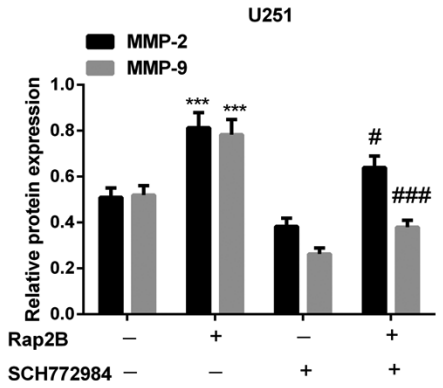

Figure 6. Effects of ERK pathway on Rap2B-induced MMP2 and MMP9 expression. An enzyme-linked immunosorbent assay showed MMP2 and MMP9 secretion in the supernatant of (A) U87 and (B) U251 glioma cells. Protein levels of MMP2 and MMP9 were determined by western blot analysis following treatment with Rap2B overexpression plasmids with or without SCH772984 in (C) U87 and (D) U251 cells. ${ }^{*} \mathrm{P}<0.05,{ }^{* * *} \mathrm{P}<0.01$ and ${ }^{* * * *} \mathrm{P}<0.001$ vs. the control group. ${ }^{\#} \mathrm{P}<0.05,{ }^{\# \#} \mathrm{P}<0.01$ and ${ }^{\# \# \#} \mathrm{P}<0.001$ vs. the overexpressed Rap2B group. MMP, matrix metalloproteinase.

As presented in Table I, the relationship between Rap2B expression and clinical characteristics of patients with GBM were detailed. It was revealed that Rap2B expression was not significantly associated with sex, age and tumor recurrence or progression status in GBM. Kaplan-Meier survival analysis indicated that patients with GBM with high expression of Rap2B showed a shorter survival time compared with those in the low expression group, but there was no significant difference between two groups (Fig. 7A). In LGG samples, as presented in Table II, the results revealed that Rap2B expression was significantly associated with tumor grade and histological type $(\mathrm{P}<0.05)$, while no significant association was observed between Rap2B expression and sex or age in this population. Further survival analysis showed that patients with LGG with higher expression of Rap2B had significantly unfavorable survival compared with those in the lower expression group (Fig. 7B; $\mathrm{P}=0.0001$ ). Moreover, high expression of Rap2B was found to be associated with poor prognosis of patients with tumor grade 3 (Fig. 7D; $\mathrm{P}=0.0006$ ), while there was no significant difference between high and low expression groups of patients with grade 2 LGG (Fig. 7C). These results indicated that Rap2B expression was closely associated with certain clinical characteristics and higher Rap2B expression was associated with poorer survival of patients with LGG. 
A

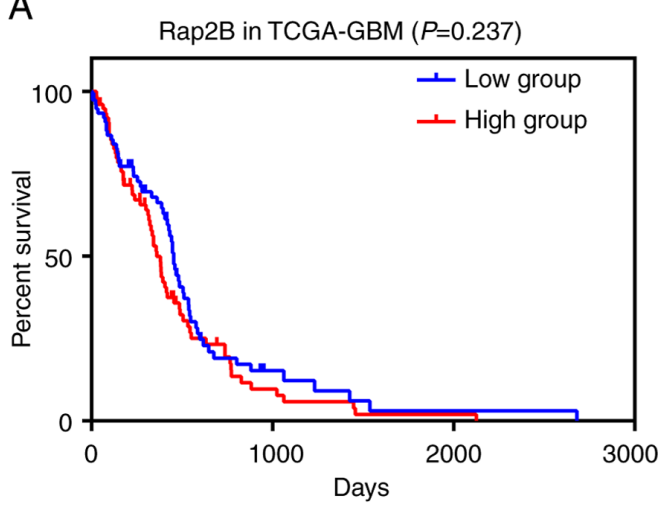

C Rap2B in Grade2 TCGA-LGG $(P=0.416)$

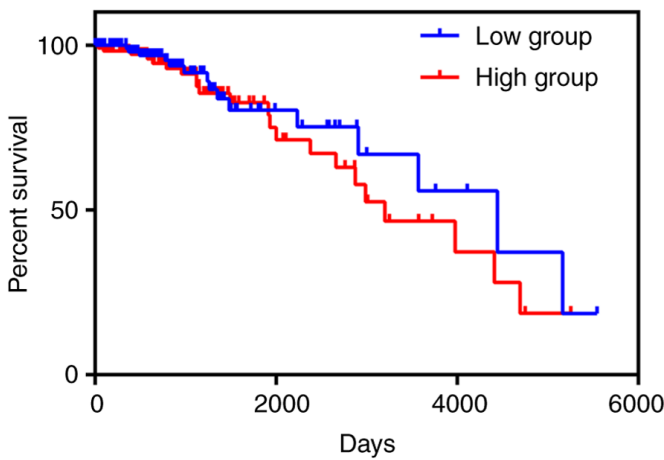

B

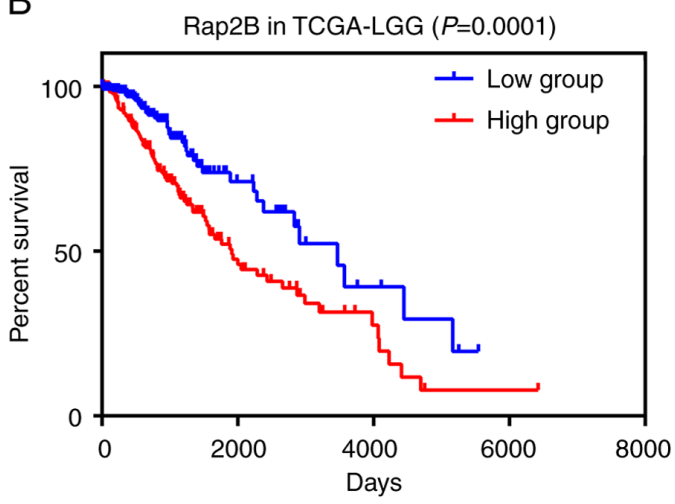

D Rap2B in Grade3 TCGA-LGG $(P=0.0006)$

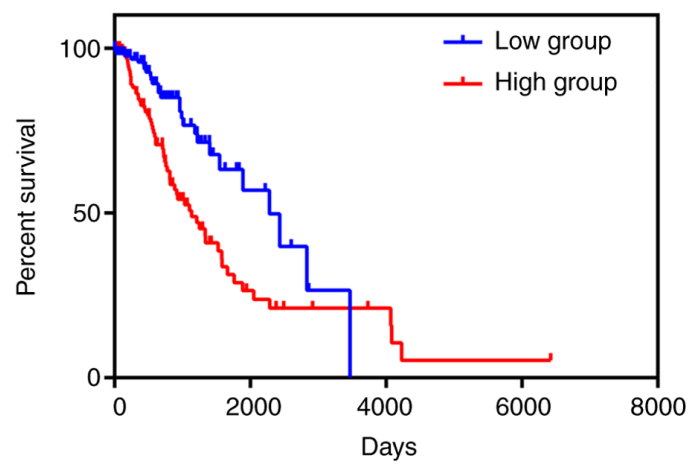

Figure 7. Kaplan-Meier survival analysis for Rap2B expression associated with overall survival of patients with GBM and LGG from TCGA database. (A) Patients with GBM and high expression of Rap2B tended to have a shorter survival time compared with those in the low group, but no significant difference between two groups. (B) Patients with LGG and increased expression of Rap2B showed poorer survival outcomes compared with those with low expression. (C) No significant difference was observed between high group and low group in patients with LGG with tumor grade 2. (D) High expression of Rap2B predicted unfavorable prognosis of patients with grade 3. GBM, glioblastoma multiforme; LGG, low-grade glioma; TCGA, The Cancer Genome Atlas.

Table I. Association of Rap2B expression with clinical features in 152 patients with glioblastoma multiforme.

\section{Rap2B expression}

Characteristics Value, $\mathrm{n}$ High group Low group P-value

\begin{tabular}{lllll}
\hline $\begin{array}{l}\text { Age, years } \\
>60\end{array}$ & 76 & 37 & 39 & 0.746 \\
$\leq 60$ & 76 & 39 & 37 & \\
$\begin{array}{l}\text { Sex } \\
\text { Female }\end{array}$ & 54 & 26 & 28 & 0.735 \\
$\quad \begin{array}{l}\text { Male } \\
\text { Recurrence or }\end{array}$ & 98 & 50 & 48 & \\
$\begin{array}{l}\text { progression } \\
\text { Yes }\end{array}$ & 84 & 44 & 40 & 0.514 \\
No & 68 & 32 & 36 & \\
\hline
\end{tabular}

\section{Discussion}

Rap2B, a member of the Ras family of the guanosine triphosphate-binding proteins, has attracted considerable attention since its identification in the early 1990s (27). A previous study reported that mutations or overexpression of Ras genes are implicated in tumorigenesis and predicted
Table II. Expression of Rap2B associated with clinical features in 509 patients with low-grade glioma.

\begin{tabular}{lcccc}
\hline & & \multicolumn{2}{c}{ Rap2B expression } & \\
\cline { 3 - 4 } & Value, & High & Low & \\
Characteristics & $\mathrm{n}$ & group & group & P-value \\
\hline Age, years & & & & \\
$>43$ & 222 & 107 & 115 & 0.499 \\
$\leq 43$ & 287 & 147 & 140 & \\
Sex & & & & \\
Female & 228 & 112 & 116 & 0.752 \\
$\quad$ Male & 281 & 142 & 139 & \\
Histological type & & & & \\
$\quad$ Astrocytoma & 192 & 114 & 78 & 0.001 \\
$\quad$ Oligoastrocytoma & 127 & 63 & 64 & \\
$\quad$ Oligodendroglioma & 190 & 77 & 113 & \\
Grade & & & & \\
$\quad$ G2 & 248 & 109 & 139 & 0.009 \\
G3 & 261 & 145 & 116 & \\
\hline
\end{tabular}

poor prognostic survival in numerous types of tumors, such as thyroid, lung and colorectal cancer (28). Rap2B is observed to be predominantly upregulated in a variety of tumors and 
acts as an oncogenic activator $(29,30)$. In the present study, Rap2B was highly expressed in both glioma cells and tissues. Additionally, it was revealed that Rap2B could facilitate the proliferation and migration of glioma cells. These findings suggested that Rap2B may have a pivotal role in the development and progression of human glioma.

Rap2B is reported to be involved in regulating cellular processes including cytoskeletal organization and cell proliferation (31). Increasing focus on the Ras signaling pathway reveals critical effects of Rap2B on tumorigenesis. Previous research reported that Rap2B exhibits oncogenic status and functions as a tumor promoter in human tumors $(20,32)$. Evidence suggests that Rap2B promotes cell proliferation, migration and invasion in cervical cancer (33). Another study revealed that increased Rap2B is associated with cell migration and invasion of human suprarenal epithelioma (34). Consistent with the results of aforementioned studies, the present study demonstrated that Rap2B enhanced the proliferation and migration of U87 and U251 cells, whereas silencing Rap2B restrained this effect, further indicating the biological function of Rap2B.

As a member of the Ras superfamily of proteins, Rap2B facilitates the activation of multiple pathways such as MAPK/ERK, PI3K/AKT and NF- $\kappa \mathrm{B}$, which are implicated in the occurrence and progression of various tumors, including breast cancer, hepatocellular carcinoma and glioma $(18,26)$. ERK is a key factor in cancer, and it is reported that the Ras/Raf/MAPK/ERK pathway modulates a series of cellular biological processes associated with tumorigenesis(35). Rap2B enhances cell proliferation through the ERK pathway, and ERK activation has a critical role in the development of cervical cancer, such as cell proliferation, migration and invasion (33). A previous study reported that Rap2B contributes to cell proliferation, migration and invasion in breast cancer via the calcium-induced ERK pathway (25). A recent study showed that Rap $2 B$ silencing inhibits the development of hepatocellular carcinoma via inhibition of the PTEN/PI3K/Akt and ERK pathways (26). Concordantly, the present study indicated that Rap2B activated the ERK signaling pathway, which enhanced the proliferation and migration of glioma cells.

Although accumulating evidence has revealed the crucial role of Rap2B in the development and progression of multiple tumors $(18,25,26)$, the potential molecular mechanism by which Rap2B promotes the proliferation and migration of glioma cells remains unknown. Tumor metastasis is induced partially by MMPs (36-38). MMP2 and MMP9 drive cell motility and tumor growth by digesting the ECM, basal lamina and adhesion proteins $(10,39)$. The present study reported that Rap2B enhanced MMP2 and MMP9 expression, while the inhibition of the ERK signaling pathway reversed Rap2B-mediated MMP2 and MMP9 expression, demonstrating that ERK signaling is required for Rap2B-induced production of MMP2 and MMP9. Since MMP2 and MMP9 are crucial to tumor growth and metastasis (40), Rap2B may enhance the proliferation and migration of glioma cells through increasing MMP2 and MMP9 expression.

To further investigate the association between Rap2B expression and certain clinical parameters, TCGA, a publicly available database, was used. Kaplan-Meier analysis showed that high expression of Rap2B was associated with overall survival time of patients with LGG, indicating a risk factor in LGG. In patients with GBM, the same trend was observed, but no significant difference was found between the high and low Rap2B expression group. It is worth noting that patients with GBM are generally treated with preoperative radiotherapy and concomitant temozolomide (41). It was postulated that the discrepancy in these statistical results may stem from these preoperative therapies in patients with GBM, thereby affecting Rap2B transcription. These findings suggested that higher Rap2B expression predicts poorer prognosis in patients with glioma. Therefore, Rap2B may be used as a novel prognostic biomarker and therapeutic target for glioma.

Of note, there were limitations in the present study. Due to the small number of adjacent normal brain tissues in TCGA-GBM dataset, it may be not adequate to accurately compare Rap2B expression between GBM tissues and matched normal tissues. So immunohistochemistry data from patients with glioma should be obtained. Furthermore, there was a lack of animal experiments in the study, but this will be the focus of the authors' future research. Xenograft experiments should be performed to confirm the present findings in vivo. Further investigation on the effect of Rap2B on glioma growth and the detailed mechanisms in glioma is the direction of our future study.

In summary, the present study revealed that Rap2B enhanced the proliferation and migration of human glioma cells via activation of ERK pathway. Additionally, Rap2B expression was upregulated in glioma and is associated with overall survival time of patients with glioma, indicating that it might act as a prognostic biomarker and therapeutic target for glioma.

\section{Acknowledgements}

Not applicable.

\section{Funding}

This research was supported by The Natural Science Foundation of Liaoning Province (grant no. 2019-ZD-0772) and The National Natural Science Foundation of China (grant nos. 81471809 and 81971639).

\section{Availability of data and materials}

The datasets used and/or analyzed during the current study are available from the corresponding author on reasonable request. Additional datasets generated and/or analyzed during the current study are available in The Cancer Genome Atlas repository, (https://portal.gdc.cancer.gov/).

\section{Authors' contributions}

GHS and ZZ designed the experiments and analyzed data. GHS contributed to performing the experiments, collecting data, and data analysis and interpretation, as well as drafting the manuscript. Both authors read and approved the final manuscript. GHS and ZZ confirm the authenticity of all the raw data 


\section{Ethics approval and consent to participate}

Not applicable.

\section{Patient consent for publication}

Not applicable.

\section{Competing interests}

The authors declare they have no competing interests.

\section{References}

1. Wen PY and Reardon DA: Neuro-oncology in 2015: Progress in glioma diagnosis, classification and treatment. Nat Rev Neurol 12: 69-70, 2016

2. Carlsson SK, Brothers SP and Wahlestedt C: Emerging treatment strategies for glioblastoma multiforme. EMBO Mol Med 6 : $1359-1370,2014$.

3. Zeng Z, Leng T, Feng X, Sun H, Inoue K, Zhu L and Xiong ZG: Silencing TRPM7 in mouse cortical astrocytes impairs cel proliferation and migration via ERK and JNK signaling pathways. PLoS One 10: e0119912, 2015.

4. Heigener DF, Gandara DR and Reck M: Targeting of MEK in lung cancer therapeutics. Lancet Respir Med 3: 319-327, 2015.

5. 5. Liu Z, Dai H, Jia G, Li Y, Liu X and Ren W: Insufficient radiofrequency ablation promotes human hepatoma SMMC7721 cell proliferation by stimulating vascular endothelial growth factor overexpression. Oncol Lett 9: 1893-1896, 2015.

6. Dong F, Tian H, Yan S, Li L, Dong X, Wang F, Li J, Li C, Cao Z, Liu X, et al: Dihydroartemisinin inhibits endothelial cell proliferation through the suppression of the ERK signaling pathway. Int J Mol Med 35: 1381-1387, 2015.

7. Figueira RC, Gomes LR, Neto JS, Silva FC, Silva ID and Sogayar MC: Correlation between MMPs and their inhibitors in breast cancer tumor tissue specimens and in cell lines with different metastatic potential. BMC Cancer 9: 20, 2009.

8. Bachmeier BE, Nerlich AG, Lichtinghagen $\mathrm{R}$ and Sommerhoff CP: Matrix metalloproteinases (MMPs) in breast cancer cell lines of different tumorigenicity. Anticancer Res 21A: 3821-3828, 2001

9. Hotary KB, YanaI,Sabeh F,LiXY,HolmbeckK,Birkedal-HansenH, Allen ED, Hiraoka N and Weiss SJ: Matrix metalloproteinases (MMPs) regulate fibrin-invasive activity via MT1-MMP-dependent and -independent processes. J Exp Med 195: 295-308, 2002

10. Forsyth PA, Wong H, Laing TD, Rewcastle NB, Morris DG Muzik H, Leco KJ, Johnston RN, Brasher PM, Sutherland G, et al: Gelatinase-A (MMP-2), gelatinase-B (MMP-9) and membrane type matrix metalloproteinase-1 (MT1-MMP) are involved in different aspects of the pathophysiology of malignant gliomas. Br J Cancer 79: 1828-1835, 1999.

11. Guo XX, An S, Yang Y, Liu Y, Hao Q and Xu TR: Rap-Interacting Proteins are Key Players in the Rap Symphony Orchestra. Cell Physiol Biochem 39: 137-156, 2016.

12. Yi L, Zhong X, Chen Z, Wang Q, Yan Y, Wang J and Deng X: MicroRNA-147b Promotes Proliferation and Invasion of Human Colorectal Cancer by Targeting RAS Oncogene Family (RAP2B). Pathobiology 86: 173-181, 2019.

13. Zhang L, Duan HB and Yang YS: Knockdown of Rap2B Inhibits the Proliferation and Invasion in Hepatocellular Carcinoma Cells. Oncol Res 25: 19-27, 2017.

14. Peng YG, Zhang ZQ, Chen YB and Huang JA: Rap2b promotes proliferation, migration, and invasion of lung cancer cells. J Recept Signal Transduct Res 36: 459-464, 2016.

15. Raaijmakers JH and Bos JL: Specificity in Ras and Rap signaling. J Biol Chem 284: 10995-10999, 2009.

16. Itoh M, Nelson CM, Myers CA and Bissell MJ: Rap1 integrates tissue polarity, lumen formation, and tumorigenic potential in human breast epithelial cells. Cancer Res 67: 4759-4766, 2007.

17. Kooistra MR, Dubé N and Bos JL: Rap1: A key regulator in cell-cell junction formation. J Cell Sci 120: 17-22, 2007.

18. Di J, Gao K, Qu D, Yang J and Zheng J: Rap2B promotes angiogenesis via PI3K/AKT/VEGF signaling pathway in human renal cell carcinoma. Tumour Biol 39: 1010428317701653, 2017.
19. Di J, Cao H, Tang J, Lu Z, Gao K, Zhu Z and Zheng J: Rap2B promotes cell proliferation, migration and invasion in prostate cancer. Med Oncol 33: 58, 2016.

20. Zhang X, He Y, Lee KH, Dubois W, Li Z, Wu X, Kovalchuk A, Zhang $\mathrm{W}$ and Huang J: Rap2b, a novel p53 target, regulates p53-mediated pro-survival function. Cell Cycle 12: 1279-1291, 2013.

21. Zhang M, Zhuang Q and Cui L: miR-194 inhibits cell proliferation and invasion via repression of RAP2B in bladder cancer. Biomed Pharmacother 80: 268-275, 2016

22. Miao F, Cui C, Zuo D, Zhang H, Mei P, Chen H, Wei S, Yang F, Zheng J, Bai J, et al: Rap2B promotes cell adhesion, proliferation, migration and invasion of human glioma. J Neurooncol 143: 221-229, 2019.

23. Livak KJ and Schmittgen TD: Analysis of relative gene expression data using real-time quantitative PCR and the 2(-Delta Delta C(T)) Method. Methods 25: 402-408, 2001

24. Louis DN, Ohgaki H, Wiestler OD, Cavenee WK, Burger PC, Jouvet A, Scheithauer BW and Kleihues P: The 2007 WHO classification of tumours of the central nervous system. Acta Neuropathol 114: 97-109, 2007.

25. Di J, Huang H, Qu D, Tang J, Cao W, Lu Z, Cheng Q, Yang J, Bai J, Zhang Y, et al: Rap2B promotes proliferation, migration, and invasion of human breast cancer through calcium-related ERK1/2 signaling pathway. Sci Rep 5: 12363, 2015.

26. Zhu L, Sun Y, Zhang S and Wang L: Rap2B knockdown suppresses malignant progression of hepatocellular carcinoma by inactivating the PTEN/PI3K/Akt and ERK1/2 pathways. Mol Cell Biochem 466: 55-63, 2020.

27. FarrellFX, OhmstedeCA, Reep BR and LapetinaEG: cDNA sequence of a new ras-related gene (rap2b) isolated from human platelets with sequence homology to rap2. Nucleic Acids Res 18: 4281, 1990.

28. Mascaux C, Iannino N, Martin B, Paesmans M, Berghmans T, Dusart M, Haller A, Lothaire P, Meert AP, Noel S, et al: The role of RAS oncogene in survival of patients with lung cancer: A systematic review of the literature with meta-analysis. $\mathrm{Br} \mathrm{J}$ Cancer 92: 131-139, 2005

29. Lv GY, Miao J and Zhang XL: Long Noncoding RNA XIST Promotes Osteosarcoma Progression by Targeting Ras-Related Protein RAP2B via miR-320b. Oncol Res 26: 837-846, 2018.

30. Zhang Q, Duan L, Xu H, Yuan J, Wu W, Wu Y, Gao Y and Cheng S: Effects of Rap2b gene on foci formation and wound-healing of NIH3T3 cells. Wei Sheng Yan Jiu 39: 403-406, 2010 (In Chinese).

31. Zhu Z, Di J, Lu Z, Gao K and Zheng J: Rap2B GTPase: Structure, functions, and regulation. Tumour Biol 37: 7085-7093, 2016

32. Xie X, Liu H, Wang M, Ding F, Xiao H, Hu F, Hu R and Mei J: miR-342-3p targets RAP2B to suppress proliferation and invasion of non-small cell lung cancer cells. Tumour Biol 36: 5031-5038, 2015

33. Li Y, Li S and Huang L: Knockdown of Rap2B, a Ras Superfamily Protein, Inhibits Proliferation, Migration, and Invasion in Cervical Cancer Cells via Regulating the ERK1/2 Signaling Pathway. Oncol Res 26: 123-130, 2018.

34. Di JH, Qu DB, Lu Z, Li LT, Cheng Q, Xin Y, Zhang LZ, Zhang Y and Zheng JN: Rap2B promotes migration and invasion of human suprarenal epithelioma. Tumour Biol 35: 9387-9394, 2014

35. Martinelli E, Morgillo F, Troiani T and Ciardiello F: Cancer resistance to therapies against the EGFR-RAS-RAF pathway: The role of MEK. Cancer Treat Rev 53: 61-69, 2017.

36. Markovic DS, Vinnakota K, Chirasani S, Synowitz M, Raguet H, Stock K, Sliwa M, Lehmann S, Kälin R, van Rooijen N, et al: Gliomas induce and exploit microglial MT1-MMP expression for tumor expansion. Proc Natl Acad Sci USA 106: 12530-12535, 2009.

37. Mentlein R, Hattermann K and Held-Feindt J: Lost in disruption: Role of proteases in glioma invasion and progression. Biochim Biophys Acta 1825: 178-185, 2012

38. Zheng X, Chopp M, Lu Y, Buller B and Jiang F: miR-15b and miR-152 reduce glioma cell invasion and angiogenesis via NRP-2 and MMP-3. Cancer Lett 329: 146-154, 2013.

39. Alaseem A, Alhazzani K, Dondapati P, Alobid S, Bishayee A and Rathinavelu A: Matrix Metalloproteinases: A challenging paradigm of cancer management. Semin Cancer Biol 56: 100-115, 2019.

40. Velinov N, Poptodorov G, Gabrovski N and Gabrovski S: The role of matrixmetalloproteinases in the tumor growth and metastasis. Khirurgiia (Sofiia) 1: 44-49, 2010 (In Bulgarian).

41. Wang C, Zhao N, Zheng Q, Zhang D and Liu Y: BHLHE41 promotes U87 and U251 cell proliferation via ERK/cyclinD1 signaling pathway. Cancer Manag Res 11: 7657-7672, 2019.

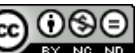

This work is licensed under a Creative Commons Attribution-NonCommercial-NoDerivatives 4.0 International (CC BY-NC-ND 4.0) License. 